\title{
Comorbidity in young patients with juvenile systemic lupus erythematosus: how can we improve management?
}

\author{
Coziana Ciurtin $^{1}$ (1) $\cdot$ George A. Robinson ${ }^{1,2} \cdot$ Ines Pineda-Torra ${ }^{3} \cdot$ Elizabeth C. Jury $^{2}$
}

Received: 3 February 2022 / Revised: 3 February 2022 / Accepted: 3 February 2022 / Published online: 17 February 2022

(c) International League of Associations for Rheumatology (ILAR) 2022

Developments in research leading to better diagnosis, treatment and ultimately improved long-term outcomes for children and adolescents with juvenile systemic lupus erythematosus (JSLE) in the last decades has increased clinicians' awareness of the role of holistic care in patient management. JSLE is a complex systemic disease associated with chronic inflammation with potential impact on many aspects of health and quality of life of young people. It is widely recognised that JSLE is associated with a higher rate of cooccurrence of other medical conditions [1,2], some directly related to the disease or treatment, and some reported as a detection artefact, as many of these patients are subjected to multiple clinical appointments and medical investigations. There is evidence that co-existent physical or mental conditions in children and adolescents negatively affect patient outcomes, irrespective of the type of illness [3,4] and require complex management associated with increased health care costs [5].

\section{Comorbidity versus multimorbidity}

Comorbidity is defined by the concomitant presence of one or more noncommunicable illnesses in addition to a primary medical condition (index disease). The term comorbidity was coined in 1970 by Alvan Feinstein, an American epidemiologist who investigated patients with rheumatic fever and

Coziana Ciurtin

c.ciurtin@ucl.ac.uk

1 Centre for Adolescent Rheumatology Research, Division of Medicine, University College London, Rayne Building, London WC1E 6JF, UK

2 Centre for Rheumatology Research, Division of Medicine, University College London, Rayne Building, London WC1E 6JF, UK

3 Centre for Cardiometabolic and Vascular Science, Department of Medicine, University College London, London WC1E 6JF, UK other medical conditions, and made significant contributions to improved chronic disease classification and the development of the field of clinical epidemiology [6]. Although historically, the focus of recognising and managing comorbidity was directed towards populations of increased age, because of an interdependent relationship between age and illness, it is increasingly recognised that comorbidities can affect people of any age.

Comorbidity and multimorbidity are considered interchangeable terms, especially in the context of approaching patient management from a secondary and tertiary care perspective, which is usually centred around a disease index. In contrast, the term multimorbidity is more patient-centric implying focus on a holistic and multi-disciplinary management approach, highly suitable in the context of a multisystem autoimmune disease such as JSLE [7].

\section{Age impact on comorbidity prevalence in general population}

Comorbidity in young people is understudied overall, despite increased awareness of the epidemiological transition of the age onset for various chronic diseases [8]. Worrying statistics from the US estimate that one in 5 children have obesity and that the prevalence of type 2 diabetes is estimated to increase by fourfold by 2050 among people younger than 20 years of age [9]. Although historically cardiovascular disease (CVD) and cardiovascular risk (CVR) are actively assessed in mature/older populations, recent research estimates that $1-3 \%$ children in the USA have hypertension, while stroke is one of the top 10 causes of death during childhood [10]. There is also evidence of increased associations of various physical and psychological illnesses in children and adolescents [11].

There are similarities between various processes involved in ageing and their related comorbidities and emerging research suggests that they could be targeted simultaneously 
for health benefits [12]. In addition, the recognised link between chronic inflammation and comorbidity, irrespective of age or underlying condition [13-15], can offer hope that targeted disease management from a younger age can address the life-long comorbidity risk.

\section{Systemic lupus erythematosus as index disease, and its impact on comorbidity risk and health care costs}

It is widely accepted that patients with systemic lupus erythematosus (SLE) are at increased risk of developing certain comorbidities, including CVD, stroke, osteoporosis and infection $[16,17]$, with recent guidelines recommending monitoring risk factors for these conditions and instituting preventative treatment in patients with both juvenile (JSLE) and adult-onset SLE [18, 19].

We know that adults with SLE are five times more likely to suffer from comorbidity compared to the age-matched general population [20], due to a combination of factors, such as disease activity, medication, and socioeconomic factors. The burden of comorbidity is significant in adults with SLE, with one study reporting that more than $50 \%$ of SLE patients reported three or more physical comorbidities [21].

Comorbidities are frequently associated with more complex patient management needs, poorer prognosis, and increased health care costs in adult-onset SLE [22, 23]. The cost of care of children with JSLE is even higher, with one study reporting that $11 \%$ of care costs are directed towards dialysis, reflecting the high burden of renal comorbidity in younger patients [24].

\section{What is different about comorbidity prevalence in JSLE compared to adult-onset SLE?}

JSLE patients have increased prevalence of renal and neuropsychiatric involvement and almost 6 times increased standardised mortality rate compared to patients with adultonset SLE [25]. A high proportion (44.2\%) of children with JSLE develop irreversible damage only 3.8 years from diagnosis, suggesting a high risk for accumulating comorbid illnesses early in life; however, there is a lack of research looking specifically into the prevalence of overall comorbidities in JSLE. The most common JSLE related damage is associated with kidney disease, scarring alopecia and cognitive impairment [26].

CVD is probably the most studied comorbidity associated with JSLE. Children with JSLE are estimated to have 100-300-fold CVD-related increased mortality compared to age-matched young controls [27]. In addition, JSLE patients are younger at the time of first CVD event (usually myocardial infarction) compared with patients with adult-onset SLE [28]. Subclinical atherosclerosis can be associated with both traditional and non-traditional CVR factors in this patient population [29], suggesting an increased risk for CVD comorbidity from early age. More than one in three patients aged 10-21 years recruited to the Atherosclerosis Prevention in Paediatric Lupus Erythematosus (APPLE) study (investigating treatment with atorvastatin for atherosclerosis prevention in JSLE) had hypertension [30], while a recent large cohort study of adults with SLE estimated its prevalence at $24.6 \%$ [21]. Dyslipidaemia was also found to be more common in JSLE than in adult-onset SLE [21, 31], while the prevalence of obesity was comparable [21,32]. One in 5 children with JSLE had osteoporosis [33], which is more than reported in adults with SLE in a recent meta-analysis [34]. Despite striking evidence that the comorbidity risk associated with JSLE is likely higher than that of adult-onset SLE, there is almost no research directed towards stratifying and managing JSLE patients based on their comorbidity index.

\section{Unmet needs for better JSLE patient stratification, comorbidity assessment and management}

Recent efforts for JSLE patient stratification based on biomarkers for organ involvement bring hope for future patienttailored and more effective treatment approaches [35], and ultimately better comorbidity prevention and management. Improved health and long-term outcomes for children and adolescents world-wide are recognised as public health priorities.

JSLE patients have an increased comorbidity risk compared to matched young healthy controls but there are differences within JSLE cohorts as they are highly heterogeneous. Patients with early onset JSLE have higher mortality and neuropsychiatric/vascular/cutaneous damage despite similar frequencies of severe cumulative manifestations [36], and they should be monitored more closely.

From an early age, children and adolescents with JSLE already acquire various CVR factors, such as hypertension, elevated triglycerides, apolipoprotein $\mathrm{B}$, haemoglobin A1c and insulin levels, as well as increased arterial stiffness, in addition to non-traditional CVR, such as elevated homocysteine and fibrinogen, when compared to matched healthy controls [37]. The key for adequate comorbidity management is the appropriate patient stratification for tailored interventions. Recent research identified lipid biomarkers, which enabled JSLE patient stratification based on their atherogenic lipid profile [38], while immunological and metabolic signatures of JSLE patients can help predict 
long-term outcomes and CVR [39, 40]. Furthermore, there is evidence that targeted therapeutic interventions to address the increased comorbidity risk in JSLE could be beneficial and acceptable to young patients. A dietary intervention in girls with JSLE stratified based on their lipid profile was associated with benefit [41], providing evidence that diet could be a suitable strategy for improving JSLE CVR profile in selected categories of patients. A tailored 3-month aerobic exercise programme in physically inactive children with JSLE ameliorated their cardiorespiratory capacity/ autonomic function, and therefore their physical comorbidity [42].

\section{What can we do better?}

Recent UK-led international collaboration efforts into implementing "treat to target" recommendations in JSLE have been met with enthusiasm from young patients and their parents [43], raising hope that some of the excessive comorbidity risk affecting these young patients could be managed in the future through tighter disease control. However, primary prevention and education is likely to have a significant role in managing children and adolescents' health overall, and the increased comorbidity risk in JSLE. Many JSLE biomarkers require further validation in ethnically and geographically diverse cohorts before implementation in clinical practice. The complex adolescent physiology and behaviour account for the under-recognised and inadequately managed genderbias affecting the comorbidity risk of young people, as well as their attitudes to health interventions $[44,45]$. The future may bring more standardised ways to assess comorbidities in young people in general, and JSLE in particular, and even a disease-focused comorbidity index to guide clinical management. There is also hope for more efficient and better targeted treatments for JSLE, with minimal toxicity. Finally, we must let young people's voice be heard and involve them in the long journey for better health in JSLE through efforts to align clinician and patient priorities.

\section{Declarations}

Disclosures None.

\section{References}

1. Chan PC, Yu CH, Yeh KW, Horng JT, Huang JL (2016) Comorbidities of pediatric systemic lupus erythematosus: a 6-year nationwide population-based study. J Microbiol Immunol Infect 49(2):257-263
2. Quilter MC, Hiraki LT, Korczak DJ (2019) Depressive and anxiety symptom prevalence in childhood-onset systemic lupus erythematosus: a systematic review. Lupus 28(7):878-887

3. Kompaniyets L, Agathis NT, Nelson JM, Preston LE, Ko JY, Belay B, et al. Underlying medical conditions associated with severe COVID-19 illness among children. JAMA Netw Open. 2021;4(6):e2111182.

4. Fazeli Farsani S, Souverein PC, van der Vorst MM, Knibbe CA, de Boer A, Mantel-Teeuwisse AK (2015) Chronic comorbidities in children with type 1 diabetes: a population-based cohort study. Arch Dis Child 100(8):763-768

5. Cohen E, Berry JG, Camacho X, Anderson G, Wodchis W, Guttmann A (2012) Patterns and costs of health care use of children with medical complexity. Pediatrics 130(6):e1463-e1470

6. Feinstein AR (1970) The pre-therapeutic classification of comorbidity in chronic disease. J Chronic Dis 23(7):455-468

7. Harrison C, Fortin M, van den Akker M, Mair F, CalderonLarranaga A, Boland F et al (2021) Comorbidity versus multimorbidity: why it matters. J Comorb 11:2633556521993993

8. Gaziano JM (2010) Fifth phase of the epidemiologic transition: the age of obesity and inactivity. JAMA 303(3):275-276

9. Imperatore G, Boyle JP, Thompson TJ, Case D, Dabelea D, Hamman RF, et al. Projections of type 1 and type 2 diabetes burden in the U.S. population aged $<20$ years through 2050: dynamic modeling of incidence, mortality, and population growth. Diabetes Care. 2012;35(12):2515-20.

10. Andes LJ, Cheng YJ, Rolka DB, Gregg EW, Imperatore G. Prevalence of prediabetes among adolescents and young adults in the United States, 2005-2016. JAMA Pediatr. 2020;174(2):e194498.

11. Pulgaron ER (2013) Childhood obesity: a review of increased risk for physical and psychological comorbidities. Clin Ther 35(1):A18-32

12. Niccoli T, Partridge L (2012) Ageing as a risk factor for disease. Curr Biol 22(17):R741-R752

13. Boehncke WH (2018) Systemic inflammation and cardiovascular comorbidity in psoriasis patients: causes and consequences. Front Immunol 9:579

14. Barter J, Kumar A, Bean L, Ciesla M, Foster TC (2021) Adulthood systemic inflammation accelerates the trajectory of age-related cognitive decline. Aging (Albany NY) 13(18):22092-22108

15. Saed Aldien A, Ganesan GS, Wahbeh F, Al-Nassr N, Altarawneh $\mathrm{H}, \mathrm{Al}$ Theyab L et al (2021) Systemic inflammation may induce cardiac injury in COVID-19 patients including children and adolescents without underlying cardiovascular diseases: a systematic review. Cardiovasc Revasc Med 35:169-178. https://doi.org/10. 1016/j.carrev.2021.04.007

16. Lee YH, Choi SJ, Ji JD, Song GG (2016) Overall and causespecific mortality in systemic lupus erythematosus: an updated meta-analysis. Lupus 25(7):727-734

17. Urowitz MB, Gladman DD, Farewell V, Su J, Romero-Diaz J, Bae SC et al (2020) Accrual of atherosclerotic vascular events in a multicenter inception systemic lupus erythematosus cohort. Arthritis Rheumatol 72(10):1734-1740

18. Groot N, de Graeff N, Avcin T, Bader-Meunier B, Brogan P, Dolezalova $P$ et al (2017) European evidence-based recommendations for diagnosis and treatment of childhood-onset systemic lupus erythematosus: the SHARE initiative. Ann Rheum Dis 76(11):1788-1796

19. Fanouriakis A, Kostopoulou M, Alunno A, Aringer M, Bajema I, Boletis JN et al (2019) 2019 update of the EULAR recommendations for the management of systemic lupus erythematosus. Ann Rheum Dis 78(6):736-745

20. Duarte-Garcia A HH, Shah N, Crowson C (2021) Multimorbidity Burden in systemic lupus erythematosus: a nationwide study. Arthritis Rheumatol 73(suppl 10) 
21. Gergianaki I, Garantziotis P, Adamichou C, Saridakis I, Spyrou G, Sidiropoulos P et al (2021) High comorbidity burden in patients with SLE: data from the community-based lupus registry of crete. J Clin Med 10(5):998. https://doi.org/10.3390/jcm10050998

22. Han GMHX (2017) Comorbid conditions are associated with emergency department visits, hospitalizations, and medical charges of patients with systemic lupus erythematosus. J Clin Rheumatol 23(1):19-25

23. Khamashta MA, Bruce IN, Gordon C, Isenberg DA, Ateka-Barrutia $\mathrm{O}$, Gayed $\mathrm{M}$ et al (2014) The cost of care of systemic lupus erythematosus (SLE) in the UK: annual direct costs for adult SLE patients with active autoantibody-positive disease. Lupus 23(3):273-283

24. Brunner HI, Sherrard TM, Klein-Gitelman MS (2006) Cost of treatment of childhood-onset systemic lupus erythematosus. Arthritis Rheum 55(2):184-188

25. Ambrose N, Morgan TA, Galloway J, Ionnoau Y, Beresford MW, Isenberg DA et al (2016) Differences in disease phenotype and severity in SLE across age groups. Lupus 25(14):1542-1550

26. Holland MJ, Beresford MW, Feldman BM, Huggins J, Norambuena X, Silva CA et al (2018) Measuring disease damage and its severity in childhood-onset systemic lupus erythematosus. Arthritis Care Res (Hoboken) 70(11):1621-1629

27. Hersh AO, Trupin L, Yazdany J, Panopalis P, Julian L, Katz P et al (2010) Childhood-onset disease as a predictor of mortality in an adult cohort of patients with systemic lupus erythematosus. Arthritis Care Res (Hoboken) 62(8):1152-1159

28. Hersh AO, von Scheven E, Yazdany J, Panopalis P, Trupin L, Julian L et al (2009) Differences in long-term disease activity and treatment of adult patients with childhood- and adult-onset systemic lupus erythematosus. Arthritis Rheum 61(1):13-20

29. Schanberg LE, Sandborg C, Barnhart HX, Ardoin SP, Yow E, Evans GW et al (2009) Premature atherosclerosis in pediatric systemic lupus erythematosus: risk factors for increased carotid intima-media thickness in the atherosclerosis prevention in pediatric lupus erythematosus cohort. Arthritis Rheum 60(5):1496-1507

30. Mulvihill E, Ardoin S, Thompson SD, Zhou B, Yu GR, King E, et al. Elevated serum complement levels and higher gene copy number of complement $\mathrm{C} 4 \mathrm{~B}$ are associated with hypertension and effective response to statin therapy in childhood-onset systemic lupus erythematosus (SLE). Lupus Sci Med. 2019;6(1):e000333.

31. Ortiz TT, Terreri MT, Caetano M, Souza FS, D’Almeida V, Sarni RO et al (2013) Dyslipidemia in pediatric systemic lupus erythematosus: the relationship with disease activity and plasma homocysteine and cysteine concentrations. Ann Nutr Metab 63(1-2):77-82

32. Sinicato NA, Postal M, Peres FA, Pelicari Kde O, Marini R, dos Santos Ade O, et al. Obesity and cytokines in childhood-onset systemic lupus erythematosus. J Immunol Res. 2014;2014:162047.

33. Compeyrot-Lacassagne S, Tyrrell PN, Atenafu E, Doria AS, Stephens D, Gilday D et al (2007) Prevalence and etiology of low bone mineral density in juvenile systemic lupus erythematosus. Arthritis Rheum 56(6): 1966-1973

34. Gu C, Zhao R, Zhang X, Gu Z, Zhou W, Wang Y et al (2019) A meta-analysis of secondary osteoporosis in systemic lupus erythematosus: prevalence and risk factors. Arch Osteoporos 15(1): 1

35. Greenan-Barrett J, Doolan G, Shah D, Virdee S, Robinson GA, Choida V et al (2021) Biomarkers associated with organ-specific involvement in juvenile systemic lupus erythematosus. Int J Mol Sci 22(14):7619. https://doi.org/10.3390/ijms22147619

36. Lopes SRM, Gormezano NWS, Gomes RC, Aikawa NE, Pereira RMR, Terreri MT et al (2017) Outcomes of 847 childhood-onset systemic lupus erythematosus patients in three age groups. Lupus 26(9):996-1001

37. Boros CA, Bradley TJ, Cheung MM, Bargman JM, Russell JL, McCrindle BW et al (2011) Early determinants of atherosclerosis in paediatric systemic lupus erythematosus. Clin Exp Rheumatol 29(3):575-581

38. Robinson GA, Waddington KE, Coelewij L, Peng J, Naja M, Wincup $\mathrm{C}$, et al. Increased apolipoprotein-B:A1 ratio predicts cardiometabolic risk in patients with juvenile onset SLE. EBioMedicine. 2021;65:103243.

39. Robinson GA, Peng J, Donnes P, Coelewij L, Naja M, Radziszewska A et al (2020) Disease-associated and patient-specific immune cell signatures in juvenile-onset systemic lupus erythematosus: patient stratification using a machine-learning approach. Lancet Rheumatol 2(8):e485-e496

40. Robinson GA, Peng J, Pineda-Torra I, Ciurtin C, Jury EC (2022) Metabolomics defines complex patterns of dyslipidaemia in juvenile-SLE patients associated with inflammation and potential cardiovascular disease risk. Metabolites 12(1):3. https://doi.org/10. 3390/metabo12010003

41. da Silva SGL, Terreri MT, Abad TTO, Machado D, Fonseca FLA, Hix $S$ et al (2018) The effect of nutritional intervention on the lipid profile and dietary intake of adolescents with juvenile systemic lupus erythematosus: a randomized, controlled trial. Lupus 27(5):820-827

42. Prado DM, Benatti FB, de Sa-Pinto AL, Hayashi AP, Gualano B, Pereira RM et al (2013) Exercise training in childhood-onset systemic lupus erythematosus: a controlled randomized trial. Arthritis Res Ther 15(2):R46

43. Smith EMD, Gorst SL, Al-Abadi E, Hawley DP, Leone V, Pilkington C et al (2021) 'It is good to have a target in mind': qualitative views of patients and parents informing a treat to target clinical trial in juvenile-onset systemic lupus erythematosus. Rheumatology (Oxford) 60(12):5630-5641

44 Karnebeek K, Thapar S, Willeboordse M, van Schayck OCP, Vreugdenhil ACE (2019) Comorbidities in primary versus secondary school children with obesity and responsiveness to lifestyle intervention. J Clin Endocrinol Metab. 104(9):3803-3811

45 Robinson GA, Peng J, Peckham H, Radziszewska A, Butler G, Pineda-Torra I et al (2021) Sex hormones drive changes in lipoprotein metabolism. iScience. 24(11): 103257

Publisher's note Springer Nature remains neutral with regard to jurisdictional claims in published maps and institutional affiliations. 